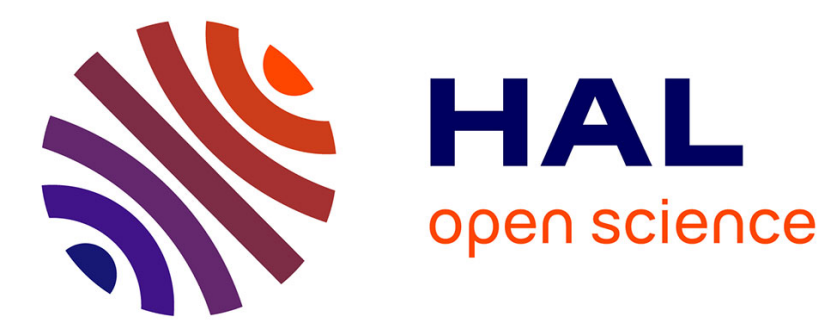

\title{
Socioeconomic status and telomere length: the West of Scotland Coronary Prevention Study
}

\author{
G David Batty, Yanzhong Wang, Scott W Brouilette, Paul Shiels, Chris
} Packard, Jashbir Moore, Nilesh Samani, Ian Ford

\section{- To cite this version:}

G David Batty, Yanzhong Wang, Scott W Brouilette, Paul Shiels, Chris Packard, et al.. Socioeconomic status and telomere length: the West of Scotland Coronary Prevention Study. Journal of Epidemiology and Community Health, 2009, 63 (10), pp.839-n/a. 10.1136/jech.2009.088427 . hal-00477895

\section{HAL Id: hal-00477895 \\ https://hal.science/hal-00477895}

Submitted on 30 Apr 2010

HAL is a multi-disciplinary open access archive for the deposit and dissemination of scientific research documents, whether they are published or not. The documents may come from teaching and research institutions in France or abroad, or from public or private research centers.
L'archive ouverte pluridisciplinaire HAL, est destinée au dépôt et à la diffusion de documents scientifiques de niveau recherche, publiés ou non, émanant des établissements d'enseignement et de recherche français ou étrangers, des laboratoires publics ou privés. 


\section{Socioeconomic status and telomere length: the West of Scotland Primary Prevention Study}

Running title: Socioeconomic status and telomere length

G. David Batty ${ }^{\mathrm{a}}$

Yanzhong Wang ${ }^{\mathrm{b}}$

Scott W. Brouilette

Paul Shiels ${ }^{\mathrm{d}}$

Chris Packard ${ }^{\mathrm{e}}$

Jasbir Moore $^{\mathrm{c}}$

Nilesh J. Samani ${ }^{\mathrm{c}}$

Ian Ford ${ }^{\mathrm{b}}$

${ }^{a}$ MRC Social \& Public Health Sciences Unit, University of Glasgow, Glasgow, UK

${ }^{\mathrm{b}}$ Robertson Centre for Biostatistics, University of Glasgow, Glasgow, UK

${ }^{c}$ Department of Cardiovascular Sciences, University of Leicester, UK

${ }^{\mathrm{d}}$ Division of Cancer Sciences and Molecular Pathology, University of Glasgow, UK

${ }^{\mathrm{e}}$ Department of Vascular Biochemistry, University of Glasgow, UK

Word count: 1250 (excluding abstract: 153)

Acknowledgments: This work was supported by a grant from the Sir Jules Thorn Charitable Trust. Nilesh J. Samani holds a Chair funded by the British Heart Foundation. David Batty is a UK Wellcome Trust Fellow (WBS U.1300.00.006.00012.01).

Competing Interest: None declared.

Licence statement: The Corresponding Author has the right to grant on behalf of all authors and does grant on behalf of all authors, an exclusive licence (or non exclusive for government employees) on a worldwide basis to the BMJ Publishing Group Ltd and its Licensees to permit this article (if accepted) to be published in JECH editions and any other BMJPGL products to exploit all subsidiary rights, as set out in our licence (http://jech.bmj.com/ifora/licence.pdf).

Correspondence to: David Batty, MRC Social \& Public Health Sciences Unit, University of Glasgow, 4 Lilybank Gardens, Glasgow, UK, G12 8RZ. E. david-b@ sphsu.mrc.ac.uk 


\begin{abstract}
Background. It has been hypothesised that socio-economically deprived people age more rapidly than their more advantaged counterparts and this is manifested in shorter telomeres. However, in the very few studies conducted, substantial uncertainty exists regarding this relationship.

Methods. In the present investigation, 1542 men in the West of Scotland Primary Prevention Study responded to a series of enquiries about their socioeconomic position (educational attainment, employment status, area-based deprivation), had their physical stature measured (a proxy for of early life social circumstances), and provided a blood specimen from which Leucocyte DNA was extracted and telomere length ascertained. Results. There was no strong evidence that any marker of these four socioeconomic position was robustly related to telomere length. The only exception was employment status: men who reported being out of work had significantly shorter telomere than those who were employed (p-value: 0.001).

Conclusion. In this cross-sectional study - the largest to date to examine the relationship - we found little evidence of an association between socioeconomic status and telomere length.
\end{abstract}




\section{Introduction}

A series of studies spanning several decades have shown that low socioeconomic status (SES) - typically indexed by education, occupational social class, income,

neighbourhood deprivation, and physical stature - is related to elevated rates of a range of chronic diseases including cardiovascular disease (CVD) and selected cancers.[1,2] Investigators have attempted to understand how socioeconomic disadvantage "gets under the skin" to give rise to this elevated disease risk. Access to resources (e.g., education and income), physical exposures in the living and working environment (e.g., housing conditions), health-related behaviours (e.g., tobacco smoking and diet), and psychological characteristics (e.g., IQ, personality disposition, psychosocial stress) appear to explain some, although by no means all, of the socioeconomic gradient.[1] Another mechanistic possibility is that, as CVD and cancer are, in part, ageing-related diseases, socioeconomic disadvantage increases mortality risk by accelerating the ageing process.

Telomere dynamics (length, attrition) capture biological ageing above and beyond chronological age, such that shorter telomeres represent increased biological senescence. Given the afore described socioeconomic variations in age-related chronic disease, and the recent observation that shorter telomere length is related to CVD risk,[3-5] one would anticipate that socioeconomic adversity would lead to reduced telomere length. However, in only three previous studies examining this relation of which we are aware, the evidence is inconclusive with positive[6] and null associations reported.[7, 8] Notably, the only positive finding of a relation between socioeconomic disadvantage and telomere length was in the largest conducted to date - a cross-sectional analyses of 1552 female twins.[6] 
In the present analysis we used the West of Scotland Primary Prevention Study

(WOSCOPS),[4] a population-based intervention for the prevention of coronary heart disease (CHD) of very similar size to the afore-described twin study. While we have previously reported on the predictive value of a series of physiological and behavioural variables for telomere length in this cohort,[4] this is the first analysis examining the impact, if any, of socioeconomic factors on this biological marker of the ageing process. In capturing socioeconomic data at the level of the individual and geographical area, we provide a comprehensive evaluation of the relation of social disadvantage with telomere length.

\section{Methods}

The WOSCOPS has been described in detail elsewhere.[9] In brief, following population-based screening, 6595 men aged 45-64 years, with no prior history of myocardial infarction, were classified as being at high risk of CHD based on an unfavourable lipid profile. The men were then randomly assigned to receive pravastatin or placebo and followed up for an average of 4.9 years. The present analyses are based on the analytical sample of a case-control study nested within this prospective trial[4] in which men who developed CHD during follow-up (cases) were matched for age and smoking status with two CHD-free controls.

Leucocyte DNA, extracted from blood obtained at recruitment and suitable for telomere length analysis, was available for 484 cases and 1058 controls. The measurement of leukocytes telomere length, which involved a quantitative PCR-based technique that compares telomere repeat sequence copy number to single-copy gene (36b4) copy number in a given sample, has been comprehensively described.[4] We have previously 
confirmed that this novel PCR assay, which is capable of high throughput, is highly reproducible.[4]

During interviews with trained research nurses, four indicators of socioeconomic position were ascertained at study induction: three at the level of the individual (education, employment status, and height) and one at the level of the neighbourhood ('Carstairs' index). Highest educational attainment was based on 4 categories (secondary school with leaving certificate [no graduation]; school leaving certificate [with graduation]; further education but no degree; university degree or similar). Employment status was categorised into four groups (unemployed, retired, invalid, employed). Height, directly measured using a standard protocol, was used as a proxy for of early life socio-economic position,[10] such that shorter persons generally originate from more impoverished backgrounds.[11-14] The Carstairs' index is a continuously scored variable, comprising four variables at postcode sector level that were judged to represent socio-economic disadvantage in the population (lack of car ownership, Registrar General's social class classification of IV or V, overcrowded households and male unemployment). Higher scores denote greater deprivation. Following a series of standard enquiries, study members also reported their alcohol intake, cigarette habit, and existing illness.[9]

We used linear regression to quantify the relation of each indicator of socioeconomic position with telomere length in which the latter was log-transformed to have an approximated normal distribution. With no evidence that the development of CHD modified the socioeconomic position--telomere length relation, data from cases and controls were pooled and adjustment made for case/control status. We first examined the association between each of our markers of socioeconomic position and covariates with 
telomere length in bivariate analyses, after which we controlled for all non-SES variables in the model.

\section{Results}

In table 1 we present the associations of the four indicators of socioeconomic position, and each covariates, with telomere length. As we have previously reported,[4] older men and those who developed CHD had, on average, shorter telomere length than those in the younger age groups and those who were CHD-free at follow-up, respectively. In unadjusted analyses, there was no strong evidence that any marker of socioeconomic position had an influence on telomere length. The only exception was employment status: men who reported being out of work had significantly shorter telomere than those who were employed. In analyses in which we adjusted for potential covariates (age, smoking, BMI, alcohol intake, existing illness, statin treatment and case/control status), the impact of unemployment on telomere length remained. Additionally, retired men appeared to have a longer telomere length than the employed although this was of borderline statistical significance.

\section{Discussion}

In the present study there was little evidence of a relationship between socio-economic disadvantage and telomere length: of the four indicators of socio-economic status utilising individual and area-based indices, there was a suggestion that only unemployed men had a significantly shorter telomere length than the employed; comparison of other employment classifications revealed no such differences. Whilst the effect for unemployed relative to the employed may be genuine, as one of several comparisons necessarily conducted in the course of these analyses, it is more likely to have occurred 
Table 1: Regression coefficients (95\% confidence interval) for the association of markers of socio-economic status with telomere length in WOSCOPS $(n=1542)$

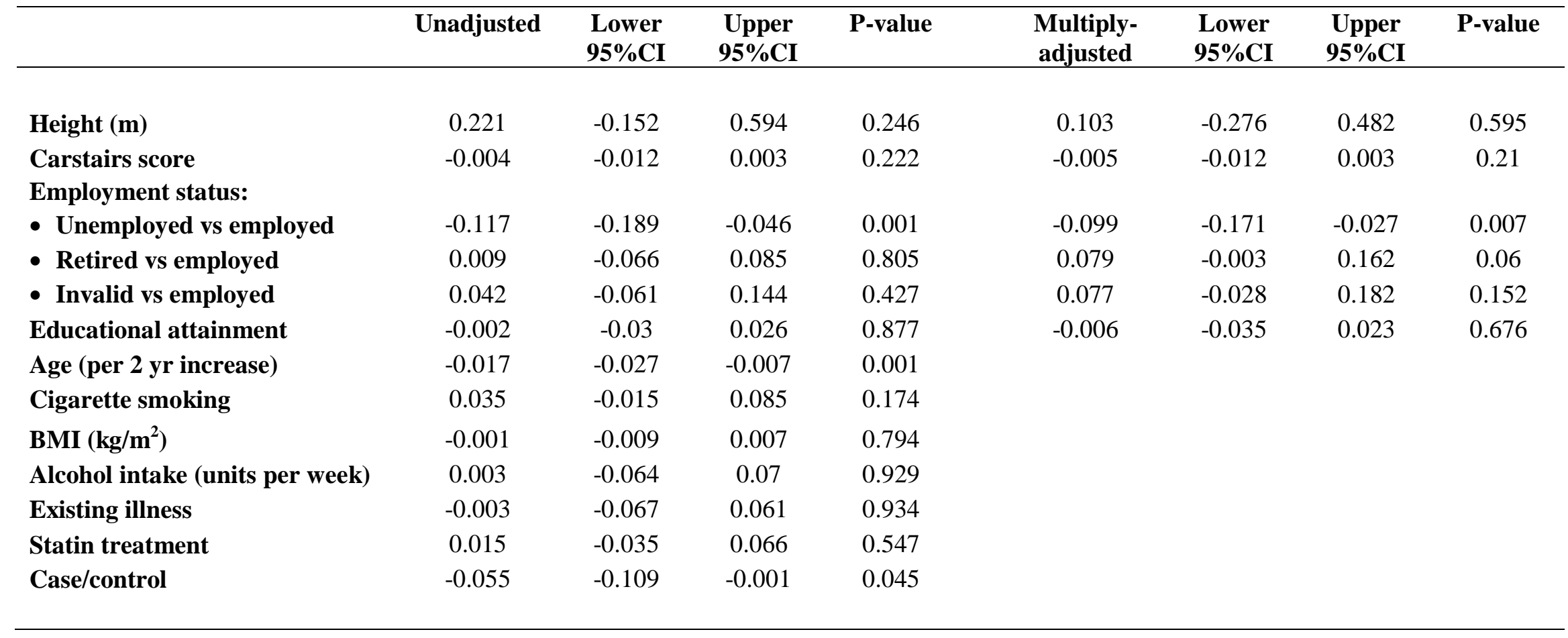

Body mass index (BMI) was computed using the standard formulae (weight $[\mathrm{kg}] / \mathrm{height}^{2}\left[\mathrm{~m}^{2}\right]$. Height, educational attainment, and Carstairs deprivation score were treated as continuous (ordinal) variables. For height and educational attainment, the regression coefficient summarises a unit increase (higher socioeconomic status) in relation to telomere length; for the Carstairs index, the unit increase reflects increasing deprivation. For age, the regression coefficient summarises a $2 \mathrm{yr}$. increase in relation to telomere length. Other covariates were dichotomised: smoking (current smoker vs. non/former), alcohol intake (alcohol consumption $\geq 20$ units per week vs. less), existing illness (diabetes/hypertension vs. neither), statin treatment (yes vs. no), and case/control (CHD vs. CHDfree). Multiple-adjustment is adjustment for age, smoking, BMI, alcohol intake, existing illness, statin treatment, and case/control status, but not the SES variables. 
by chance. Further, in the UK, 'unemployment' represents a heterogeneous group of individuals: whilst it will comprise people in poverty, it will also include those who are not seeking work because they are independently financially secure. This therefore complicates data interpretation. Of the three previous studies in this field,[6-8] in only one, an analysis of female twins,[6] did occupational social class reveal any association with telomere length. In cross-sectional analyses in which a six category scale of this index was collapsed into two groups[6] - manual and non-manual - women in the former occupations had markedly shorter telomere lengths than those in the latter. However, in analyses which the authors utilised the full range of social class categories, there was no evidence of a relationship; nor were the other socioeconomic measures - income and education - associated with telomere length.

The strengths of this study lie in its size and its population-based sampling. It is not, however, without its shortcomings such as the absence of measurement of other recognised socio-economic indicators -- income, occupational social class, housing tenure, and household amenities -- and its focus on men, although we are not aware of any biologically or socially plausible explanation for a differential socio-economic statustelomere length association according to gender.

In conclusion, the balance of evidence to date does not provide clear evidence of a SEStelomere length gradient; further examination may be justified. Ideally, these would utilise a prospective cohort design. 


\section{Box. What this paper adds}

\section{What is already known on this subject?}

- It has been hypothesised that socio-economically deprived people age more rapidly than their more advantaged counterparts, and this is manifested in shorter telomeres.

- In the very few studies conducted, substantial uncertainty exists regarding this relationship.

\section{What does this study add?}

- In this cross-sectional study - the largest to date to examine the relationship - we found little evidence of an association between socioeconomic status and telomere length. 


\section{References}

1. Macintyre S. Social inequalities and health in the contemporary world: comparative overview. In Strickland S, Shetty P, eds. Human biology and social inequality (39th symposium volume of the Society for the Study of Human Biology), Cambridge: Cambridge University Press, 1998.

2. Davey Smith G, Lynch J. Socioeconomic differentials. In Kuh D, Ben Shlomo Y, eds. A life course approach to chronic disease epidemiology, pp 77-115. Oxford: Oxford Univerity Press, 2004.

3. Cawthon RM, Smith KR, O'Brien E, Sivatchenko A, Kerber RA. Association between telomere length in blood and mortality in people aged 60 years or older. Lancet 2003;361:393-5.

4. Brouilette SW, Moore JS, McMahon AD, Thompson JR, Ford I, Shepherd J et al. Telomere length, risk of coronary heart disease, and statin treatment in the West of Scotland Primary Prevention Study: a nested case-control study. Lancet 2007;369:107-14.

5. Brouilette S, Singh RK, Thompson JR, Goodall AH, Samani NJ. White cell telomere length and risk of premature myocardial infarction. Arterioscler.Thromb.Vasc.Biol. 2003;23:842-6.

6. Cherkas LF, Aviv A, Valdes AM, Hunkin JL, Gardner JP, Surdulescu GL et al. The effects of social status on biological aging as measured by white-blood-cell telomere length. Aging Cell 2006;5:361-5.

7. Harris SE, Deary IJ, MacIntyre A, Lamb KJ, Radhakrishnan K, Starr JM et al. The association between telomere length, physical health, cognitive ageing, and mortality in non-demented older people. Neurosci.Lett. 2006;406:260-4.

8. Adams J, Martin-Ruiz C, Pearce MS, White M, Parker L, Von Zglinicki T. No association between socio-economic status and white blood cell telomere length. Aging Cell 2007;6:125-8.

9. The WOSCOPS Study Group. Screening experience and baseline characteristics in the West of Scotland Coronary Prevention Study. The WOSCOPS Study Group. West of Scotland Coronary Prevention Study. Am J Cardiol. 1995;76:485-91.

10. Gunnell D. Can adult anthropometry be used as a 'biomarker' for prenatal and childhood exposures? Int J Epidemiol 2002;31:390-4.

11. Batty GD, Shipley MJ, Langenberg C, Marmot MG, Davey Smith G. Adult height in relation to mortality from 14 cancer sites in men in London (UK): evidence from the original Whitehall study. Ann.Oncol. 2006;17:157-66.

12. Batty GD, Gunnell D, Langenberg C, Davey Smith G, Marmot MG, Shipley MJ. Adult height and lung function as markers of life course exposures: associations with risk factors and cause-specific mortality. Eur.J.Epidemiol. 2006;21:795-801.

13. Langenberg C, Shipley MJ, Batty GD, Marmot MG. Adult socioeconomic position and the association between height and coronary heart disease mortality: findings from 33 years of follow-up in the whitehall study. Am J Public Health 2005;95:62832.

14. Batty GD,.Leon DA. Socio-economic position and coronary heart disease risk factors in children and young people: Evidence from UK epidemiological studies. Eur J Public Health 2002;12:263-72. 